\title{
Inhibitory Effect of Intravenous GABA Antagonists on Gastric Acid Secretion Stimulated by Secretagogues in Rats
}

\author{
Wen-Chuan LIN, Shingo YANO and Kazuo WATANABE* \\ Laboratory of Chemical Pharmaco!ogy, Department of Drug Evaluation and \\ Toxicological Sciences. Faculty of Pharmaceutical Sciences. \\ Chiba University, 1-33 Yayoi-cho, Chiba 260, Japan
}

Accepted November 4, 1988

\begin{abstract}
Effect of intravenous administration of GABA antagonists on gastric acid secretion in perfused stomachs was studied in rats anesthetized with urethane. Bethanechol ( $\mathrm{BeCh}$ )-stimulated acid secretion was definitely inhibited by bicuculline, a GABA antagonist, and strychnine, a glycine antagonist, but not by picrotoxin and pentylenetetrazol, GABA antagonists. The inhibitory effect of bicuculline and strychnine was accompanied by vigorous convulsions. Only the bicucullineinduced inhibition was still seen in d-tubocurarine paralyzed rats, and it was abolished in spinal rats. 2-Deoxy-D-glucose (2-DG)-stimulated acid secretion was apparently depressed by all the GABA antagonists of bicuculline, picrotoxin and pentylenetetrazol. The inhibitory effect of picrotoxin, but not bicuculline, on the 2-DG stimulation was still elicited in spinal rats. Inhibition of acid secretion stimulated by pentobarbital, a centrally acting secretagogue, was produced by picrotoxin and pentylenetetrazol in spinal rats. These findings suggest that bicuculline acts centrally to inhibit acid secretion stimulated both peripherally by $\mathrm{BeCh}$ and centrally by 2-DG, besides nonspecific mechanisms due to convulsions, and the action would be directed to centers which are implicated in stimulation of the sympatho-adrenomedullary system; picrotoxin and pentylenetetrazol also act centrally to inhibit 2-DG- or pentobarbital-stimulated acid secretion through depression of the central vagal tone which leads to inhibition of gastric acid secretion.
\end{abstract}

The role of gamma-aminobutyric acid (GABA) as an inhibitory neurotransmitter in the mammalian nervous system is wellestablished. However, it is difficult to fully understand the physiological significance of various responses to the administration of GABA agonists or antagonists. This would result from the fact that GABAergic nerve cell bodies and terminals are found in virtually all areas of the central nervous system, and autoreceptors, which act to inhibit GABA release, are also located on the GABA terminals (1).

Recently, we observed that 2-deoxy-Dglucose (2-DG) - or bethanechol (BeCh)stimulated gastric acid secretion was depressed by picrotoxin, a GABA antagonist,

\footnotetext{
* To whom a!l correspondence should be addressed.
}

when it was injected into the lateral cerebroventricle. In contrast, gastric acid secretion was elicited after injection of picrotoxin into the lateral hypothalamus or ventromedial hypothalamus (2). On the other hand, we demonstrated that pentobarbital, which is reported to enhance GABAergic mediation and to exert a GABA-mimetic action (3). stimulates gastric acid secretion in the perfused stomach preparation (4). More recently, we also found that under a 2-DGstimulated condition, intravenous injection of pentobarbital produced a reduction of the secretory response to 2-DG, but lateral cerebroventricular injection of the drug produced an augmenting effect on the 2-DG secretory response (5). Based on these findings, it is suggested that effects of GABAergic agonists or antagonists on gastric acid 
secretion greatly vary with their administration route or their mode of action on the secretory controlling mechanism in the brain.

In the previous report (6), we demonstrated that pentobarbital-stimulated gastric acid secretion was greatly inhibited by picrotoxin and pentylenetetrazol, but was slightly depressed by bicuculline. The purpose of the present study was to further investigate the effect of systemic administration of representative GABA antagonists, bicuculline and picrotoxin, on gastric acid secretion stimulated by $\mathrm{BeCh}$ and $2-\mathrm{DG}$.

\section{Materials and Methods}

Animals: Male Wistar rats weighing 220$270 \mathrm{~g}$ were used. The animals were housed under controlled environmental conditions $\left(24 \pm 1^{\circ} \mathrm{C}\right.$, illuminated between 07:00-19:00 $\mathrm{hr}$ ) and fed on commercial rats chow (Oriental Yeast Co., Ltd., Japan). The rats were fasted for $24 \mathrm{hr}$ before each experiment, but were allowed free access to water.

Experimental procedures: Both intact and spinal animals were used in the present experiments. The rats were i.p. anesthetized with urethane at $1.35 \mathrm{~g} / \mathrm{kg}$. Spinal rats were transected at the $\mathrm{C} 1-\mathrm{C} 2$ spinal level and were artificially respired with room air. A cannula was inserted into the trachea, and the esophagus was ligated. The abdomen was then opened, the pylorus was ligated, and a dual polyethylene gastric cannula was placed through a smal! incision in the forestomach. The lumen was perfused with saline solution, and the perfusate was automatically titrated in a reservoir with $10 \mathrm{mM}$ $\mathrm{NaOH}$ using a pH stat as described previously (4). The femoral vein was cannulated for administration of drugs. Rectal temperature was maintained at $36 \pm 1{ }^{\circ} \mathrm{C}$ by intermittent heating with an infrared lamp.

Drugs: The drugs used were 2-deoxy-Dglucose (Nakarai, Kyoto), picrotoxin, strychnine nitrate (Wako, Osaka), bethanechol chloride, bicuculline (Sigma, St. Louis, MO), pentylenetetrazol, pentobarbital sodium (Tokyo-Kasei, Tokyo), and d-tubocurarine chloride (Yoshitomi, Osaka). Bicuculline dissolved in $100 \mathrm{mM} \mathrm{HCl}$ was adjusted to $\mathrm{pH}$ 5.5 with $100 \mathrm{mM} \mathrm{NaOH}$. Pentobarbital sodium was dissolved in propylene glycol.
$40 \mathrm{v} / \mathrm{v} \%$, and ethanol, $10.5 \mathrm{v} / \mathrm{v} \%$ (50 $\mathrm{mg}$ in $1 \mathrm{ml})$. The other drugs were dissolved in saline. Doses of drugs were expressed as the amount of the salt.

Statistical analyses were made by one-way analysis of variance (ANOVA) coupled with the Dunnett test.

\section{Results}

Effect of bicuculline, picrotoxin, pentylenetetrazol and strychnine on BeCh-stimulated gastric acid secretion: All drugs were injected i.v. $20 \mathrm{~min}$ after $\mathrm{BeCh}$ (2 mg/kg, s.c.) administration. Their doses were effective ones which were used in the previous report (6). The amount of acid output during the first 2 $\mathrm{hr}$ of BeCh-stimulated gastric acid secretion was $325.6 \pm 41.4 \mu \mathrm{Eq}(n=5)$. Bicuculline (2 $\mathrm{mg} / \mathrm{kg})$ and strychnine $(2.5 \mathrm{mg} / \mathrm{kg})$ produced a definite inhibition of BeCh-stimulated acid secretion. while neither picrotoxin $(5 \mathrm{mg} / \mathrm{kg}$ ) nor pentylenetetrazol $(40 \mathrm{mg} / \mathrm{kg}$ ) affected the BeCh-stimulated acid secretion (Table 1 and Fig. 1). Both bicuculline and strychnine elicited vigorous convulsions during the first $15 \mathrm{~min}$ period. Weak clonic convulsions were also observed after picrotoxin administration. No convulsions were evoked with pentylenetetrazol.

Effect of bicuculline and strychnine on $\mathrm{BeCh}$-stimulated gastric acid secretion in dtubocurarine paralyzed rats or spinal rats: Bicuculline (2 $\mathrm{mg} / \mathrm{kg})$ or strychnine $(2.5$ $\mathrm{mg} / \mathrm{kg}$ ) was i.v. administered $20 \mathrm{~min}$ after $\mathrm{BeCh}$ injection. To prevent convulsions, $d$ tubocurarine $(0.075 \mathrm{mg} / \mathrm{kg}$, i.v.) was injected 5 min before bicuculline or strychnine administration, and the rats were artificially respired with room air. The amount of acid output during the first $2 \mathrm{hr}$ of $\mathrm{BeCh}(2 \mathrm{mg} / \mathrm{kg}$, s.c.) stimulated gastric acid secretion in $d$ tubocurarine treated rats was $286.7 \pm 47.8$ $\mu \mathrm{Eq}(n=5)$. In these animals, the inhibitory effect of strychnine, but not bicuculline, on the BeCh-stimulated acid secretion was completely prevented (Table 2 and Fig. 2). In spinal rats, the inhibitory effect of bicuculline on the BeCh-stimulated acid secretion was abolished (Table 2 and Fig. 2). Although a smaller dose of $\mathrm{BeCh}$ was injected for acid stimulation $(0.5 \mathrm{mg} / \mathrm{kg}$, s.c.: $188.7 \pm 18.2 \mu \mathrm{Eq}$ during the first $2 \mathrm{hr} ; \mathrm{n}=5$ ), two of six animals 


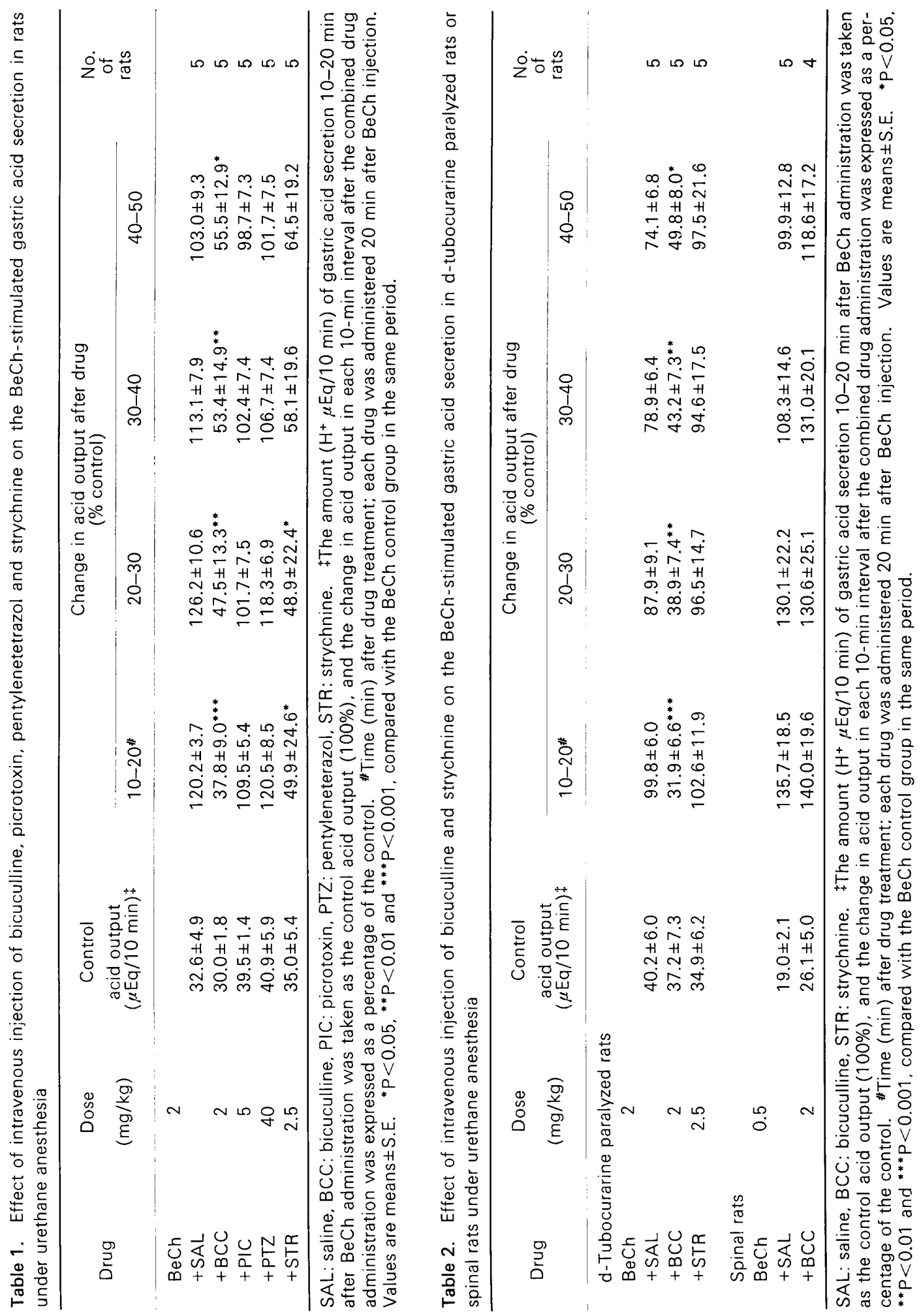



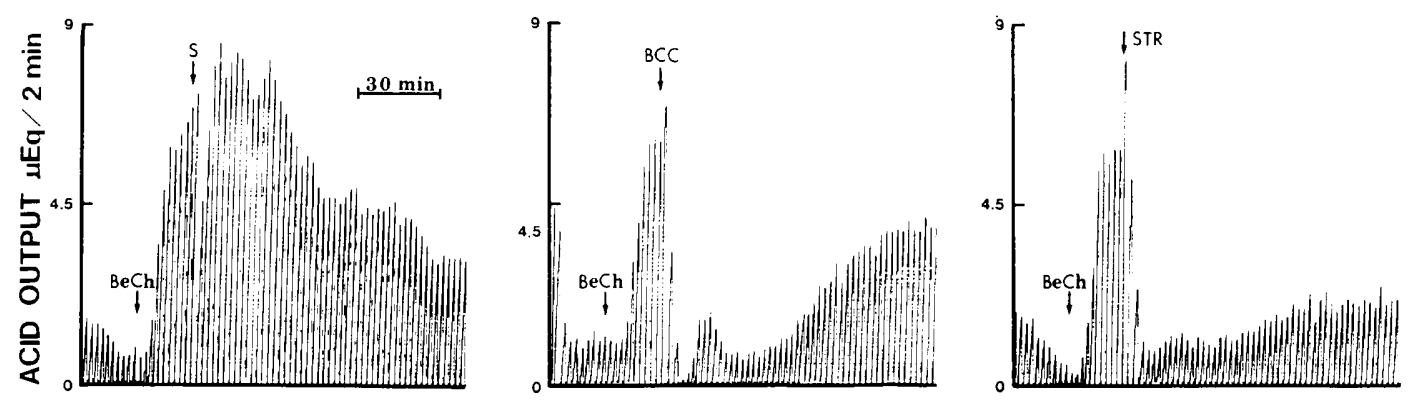

Fig. 1. Typica! tracings of the effect of saline (S), bicuculline (BCC) and strychnine (STR) on BeChstimulated gastric acid secretion in perfused stomach of rats under urethane anesthesia. BCC $(2 \mathrm{mg} / \mathrm{kg})$ or STR $(2.5 \mathrm{mg} / \mathrm{kg})$ was i.v. administered $20 \mathrm{~min}$ after BeCh $(2 \mathrm{mg} / \mathrm{kg}$. s.c.) injection. Ordinate scale: the rate of acid secretion $\left(\mathrm{H}^{+} \mu \mathrm{Eq} / 2 \mathrm{~min}\right)$. Abscissa scale: chart speed $(30 \mathrm{~mm} / 30 \mathrm{~min})$.
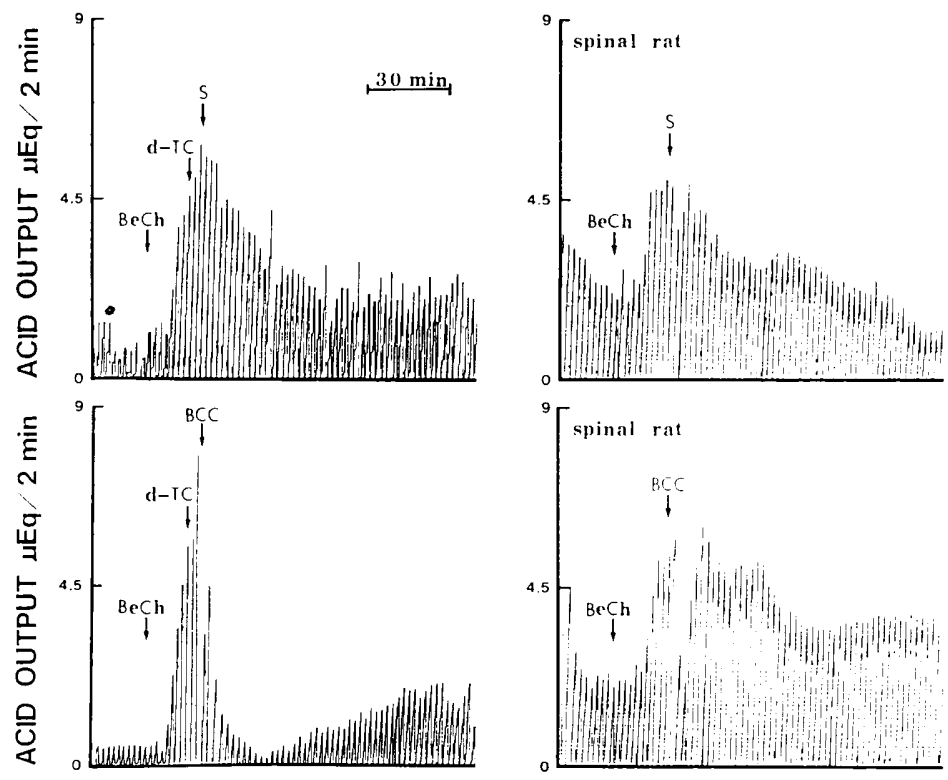

Fig. 2. Typical tracings of the effect of intravenous injection of bicuculline (BCC) on the BeCh-stimulated acid secretion in $d$-tubocurarine ( $d-T C$ ) paralyzed rats (left) or spinal rats (right) under urethane anesthesia. BCC (2 mg/kg) was i.v. administered $20 \mathrm{~min}$ after BeCh injection. The dose of BeCh was 2 $\mathrm{mg} / \mathrm{kg}$ in $\mathrm{d}$-tubocurarine paralyzed rats or $0.5 \mathrm{mg} / \mathrm{kg}$ in spinal rats, respectively. Ordinate scale; the rate of acid secretion $\left(\mathrm{H}^{+} \mu \mathrm{Eq} / 2 \mathrm{~min}\right)$. Abscissa scale: chart speed $(30 \mathrm{~mm} / 30 \mathrm{~min})$.

died about 40 min after bicuculline administration. In these two animals, however, no depressive effect on the secretory response to $\mathrm{BeCh}$ was found in the initial $30 \mathrm{~min}$ after bicuculline administration.

Effect of bicuculline, picrotoxin and pentylenetetrazol on 2-DG-stimulated gastric acid secretion: All drugs were i.v. administered $50 \mathrm{~min}$ after 2 -DG $(200 \mathrm{mg} / \mathrm{kg}$, i.v. $)$ injection. The amount of acid output during the first 2 hr of 2-DG-stimulated acid secretion was $317 \pm 76.2 \mu \mathrm{Eq} \quad(n=5)$. Administration of bicuculline (2 $\mathrm{mg} / \mathrm{kg}$ ) markedly depressed the secretory response to 2-DG for more than one hour (Table 3). The inhibitory effect of picrotoxin $(5 \mathrm{mg} / \mathrm{kg}$ ) on the 2-DG. stimulated acid secretion lasted for about 40 min. The inhibitory effect of pentylenetetrazol $(40 \mathrm{mg} / \mathrm{kg}$ ) was gradually elicited. Bicuculline produced vigorous convulsions, 


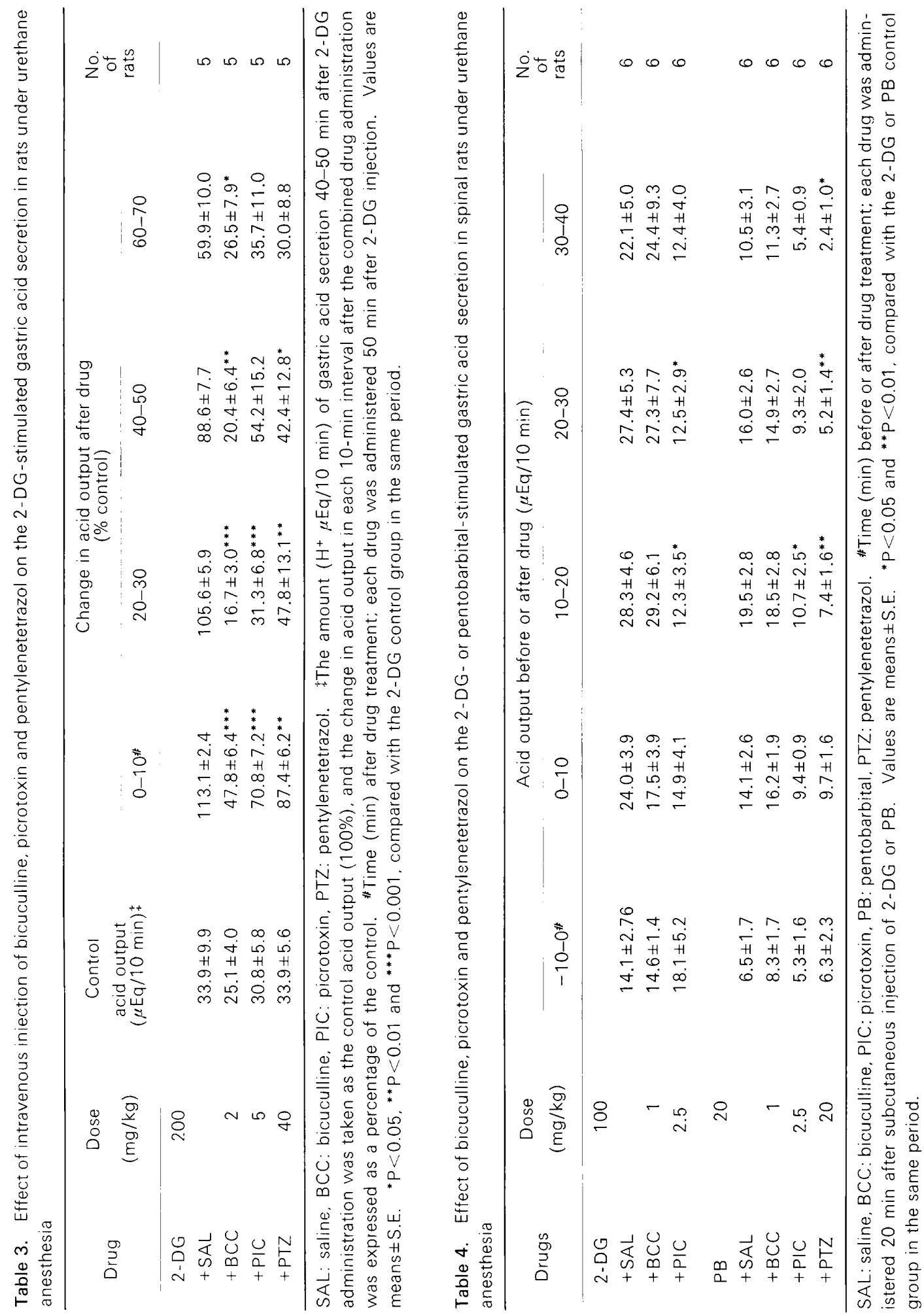


and picrotoxin caused clonic convulsions.

Effect of bicuculline, picrotoxin and pentylenetetrazol on 2-DG- or pentobarbitalstimulated gastric acid secretion in spinal rats: When 2-DG (100 mg/kg, s.c.) or pentobarbital $(20 \mathrm{mg} / \mathrm{kg}$, s.c.) was used as a secretagogue, each amount of acid output during the first $90 \mathrm{~min}$ after administration was $164.8 \pm 27.3 \mu \mathrm{Eq}(n=6)$ or $89.9 \pm 17.3$ $\mu \mathrm{Eq}(\mathrm{n}=6)$, respectively. Picrotoxin $(2.5 \mathrm{mg} /$ $\mathrm{kg})$, bicuculline $(1 \mathrm{mg} / \mathrm{kg})$ and pentylenetetrazol $(20 \mathrm{mg} / \mathrm{kg})$ were administered $20 \mathrm{~min}$ after 2-DG or pentobarbital administration; their doses were halved as compared with those used in the experiment on non-spinal intact rats. The secretory response to $2-D G$ was moderately but significantly reduced by picrotoxin (Table 4). The secretory response to pentobarbital was definitely inhibited by picrotoxin and pentylenetetrazol. However, bicuculline produced no change in the secretory responses to $2-D G$ and pentobarbital.

\section{Discussion}

The present results showed that bicuculline, a GABA antagonist, and strychnine, a glycine antagonist, inhibited BeCh-stimulated gastric acid secretion at a dose sufficient to evoke vigorous convulsions. The possibility existed that their inhibitory effects were derived indirectly from the elicited convulsions. dTubocurarine administration was done to exclude this possibility. The inhibition of BeCh-stimulated secretion by strychnine disappeared in d-tubocurarine paralyzed rats, and it was suggested that a relationship between the degree of convulsions and the inhibition of acid secretion by strychnine existed. It is reported that complex changes in the cardiovascular system occur during strychnine convulsions by the effects of the drug on vasomotor centers (7). However, it is unknown whether those cardiovascular changes are responsible for the strychnine inhibition of acid secretion. The inhibition of BeCh-stimulated secretion by bicuculline was attenuated in spinal rats, although not in $d$ tubocurarine paralyzed rats. Based on these findings, we postulate that bicuculline acts centrally to inhibit the BeCh-stimulated secretion through a peripheral antisecretory mechanism(s) such as sympatho-adrenal activation, besides nonspecific mechanisms due to convulsions. Several studies show that GABA antagonists including bicuculline acted in the forebrain to elicit an increase in blood pressure and heart rate via a sympathetically mediated pathway (8-10). In addition, it is reported that gastric acid secretion is depressed by the excitation of sympathetic outflow (11) or sympathoadrenomedullary outflow (12). Moreover, the possibility remained that the inhibitory effect of bicuculline on gastric secretion was due to the release of vasopressin from the neurohypophysis into the systemic circulation. However, this could be excluded by the fact that such a release of vasopressin by bicuculline occurs even in spinal rats (13, 14). On the other hand, picrotoxin and pentylenetetrazol, GABA antagonists, produced no change in the BeCh-stimulated gastric acid secretion. Injection of picrotoxin into the lateral cerebroventricle produced an inhibition of acid secretion stimulated by $\mathrm{BeCh}$ (2). Therefore, it is suggested that the intravenous injection of picrotoxin did not act centrally on the same site as the lateral cerebroventricular injection. As for the central effect of pentylenetetrazol, there was evidence suggesting that pentylenetetrazol acts on the picrotoxin site of the GABA receptor in the brain (15).

Centrally stimulated gastric acid secretion bv 2-DG was inhibited by GABA antagonists such as bicuculline, picrotoxin and pentylenetetrazol. As regards to central GABAergic involvements in gastric acid secretion, it is reported that muscimol, a GABA agonist. acted centrally to stimulate acid secretion through activation of parasympathetic outflow to the stomach, and the stimulatory response was antagonized by bicuculline (16). Accordingly, it may be reasonable to speculate that there is an inhibitory effect of the GABA antagonists on the 2-DG secretory response in association with depression of the central vagal tone. In spinal rats, the inhibition of gastric acid secretion was still produced by picrotoxin, but not by bicuculline. This finding suggests that picrotoxin inhibits the 2-DG-stimulated secretion via depression of the central vagal tone, but this is not the case 
for bicuculline. In addition, we previously demonstrated that pentobarbital-stimulated gastric acid secretion was markedly inhibited by picrotoxin and pentylenetetrazol, but slightly depressed by bicuculline (6). The weak antagonism of bicuculline might be associated with the fact that the sympathoadrenal activation by bicuculline was depressed by pentobarbital $(17,18)$. In the present study, picrotoxin and pentylenetetrazol, but not bicuculline, also produced an inhibition of the secretory response to pentobarbital in spinal rats. These findings suggest that picrotoxin and pentylenetetrazol act centrally to inhibit the pentobarbitalstimulated secretion via a vagally mediated pathway. In contrast, the inhibitory effect of bicuculline may be produced through antisecretory mechanisms not relating to the vagal tone.

The inhibitory effect of bicuculline on acid secretion stimulated by BeCh, 2-DG and pentobarbital was not obsreved in spinal rats. On the other hand, the picrotoxin-induced inhibition of gastric acid secretion stimulated by 2.-DG and pentobarbital was observed even in spinal rats. Thus, the inhibiting effects of these GABA antagonists on gastric acid secretion stimulated by BeCh, 2-DG and pentobarbital were not considered to be the same with regards to their association with the central GABA receptor. This might be explained by the speculation that the GABA receptor is a complex entity composed of at least three drug receptor sites: the GABA recognition site which is blocked by bicuculline, the benzodiazepine receptor site and the picrotoxin/barbiturates recognition site(s) $(19,20)$

Finally, it is suggested from the present results, along with the above speculation, that bicuculline acts centrally to inhibit acid secretion stimulated both peripherally by BeCh and centrally by $2-D G$, besides nonspecific mechanisms due to convulsions, and the action would be directed to centers which are implicated in stimulation of the sympathoadrenomedullary system, resuiting in inhibition of gastric acid secretion; picrotoxin and pentylenetetrazo! also act centrally to inhibit 2-DG- or pentobarbital-stimulated acid secretion through depression of the central vagal tone which leads to inhibition of gastric acid secretion. It is proposed that the different inhibitory effects of these GABA antagonists are associated with a complex entity of the central GABA receptor.

Acknowledgments: This study was supported in part by Grant-in-Aids for Scientific Research (No. 63480461 and No. 63571033) from the Ministry of Education, Science and Culture of Japan.

\section{References}

1 Enna, S.J.: GABA receptcr pharmacology: functional considerations. Biochem. Pharmacol. 30, 907-913 (1981)

2 Lin, W.C., Yano. S. and Watanabe, K.: Centrally acting stimulatory effect of pentobarbital on gastric acid secretion: role of hypothalamic GABAergic system. Exp. Ulcer (in press)

3 Willow, M. and Johnston, G.A.R.: Pharmacology of barbiturates: electrophysiological and neurochemical studies. Int. Rev. Neurobiol. 24, 15-49 (1983)

4 Watanabe, K., Yano, S. and Lin, W.C.: Stimulatory effect of pentobarbital and some anesthetics on gastric secretion in the continuously perfused stomach in rats under urethane anesthesia. Japan. J. Pharmacol. 44, 63-69 (1987)

5 Yano, S., Lin, W.C. and Watanabe, K.: Effect of pentobarbital on gastric acid secretion elicited by secretagogues or electrical vagal stimulation in rats under urethane anesthesia. J. Pharmac sbiodyn. 12, 43-49 (1989)

6 Lin, W.C., Yano, S. and Watanabe, K.: Possible involvement of central GABAergic system in pentobarbital-stimulated gastric acid secretion in the perfused rat stomach preparation. Eur. J. Pharmacol. 149, 33-39 (1988)

7 Franz, D.N.: Central nervous stimulants. In The Pharmacological Basis of Therapeutics (7th edition), Edited by Gilman, A.G., Goodman, L.S. Rall, T.W. and Murad, F., p. 582-588, MacMillan Publishing Company, New York (1985)

8 DiMicco, J.A. and Gillis, R.A.: Neuro-cardiovascular effects produced by bicuculline in the cat. J. Pharmacol. Exp. Ther. 210, 1-6 (1979)

9 DiMicco, J.A. and Abshire, V.M.: Evidence for GABAergic inhibition of a hypothalamic sympathoexcitatory mechanism in anesthetized rats. Brain Res. 402, 1-10 (1987)

10 DiMicco, J.A., Hamilton, B.L. and Gillis, R.A.: Central nervous system sites involved in the cardiovascular effects of picrotoxin. J. Pharmacol. Exp. Ther. 203, 64-71 (1977)

11 Shafer, P.W. and Kittle, C.F.: The relation of the autonomic nervous system to gastric secretion 
with particular reference to the sympathetic nerves. Surgery 29, 1-10 (1951)

12 Yokotani, K., Yokotani, K., Okuma, Y. and Osumi, Y.: Sympathoadrenomedullary system mediation of the prostaglandin $E_{2}$-induced central inhibition of gastric acid output in rats. J. Pharmacol. Exp. Ther. 244, 335-340 (1988)

13 Cate!li, J.M., Giakas, W.J. and Sved, A.F.: GABAergic mechanisms in nucieus tractus solitarius alter blood pressure and vasopressin release. Brain Res. 403, 279-289 (1987)

14 Wible, J.H. and DiMicco, J.A.: Biphasic effects of systemically administered GABA antagonists on cardiac vagal activity. Brain Res. 363, 279289 (1986)

15 Ticku, M.K. and Maksay, G.: Convulsant/ depressant site of action at the allosteric benzodiazepine-GABA receptor-ionophore complex. Life Sci. 33, 2363-2375 (1983)
16 Levine, A.S., Morley, J.E., Kneip, J., Grace, M. and Silvis, S.E.: Muscimol induces gastric acid secretion after central administration. Brain Res. 229, 270-274 (1981)

17 Baum, D., Halter, J.B., Taborsky, G.J. and Porte, D.: Pentobarbital effects on plasma catecho!amines: temperature, heart rate, and blood pressure. Am. J. Physiol. 248, E95-E100 (1985)

18 Taborsky, G.J., Halter, J.B., Baum, D., Best, J.D. and Porte, D.: Pentobarbital anesthesia suppresses basal and 2-deoxy-D-glucosestimulated plasma catecholamines. Am. J. Physiol. 247, R905-R910 (1984)

19 Enna, S.J.: Biochemical and electrophysiological characteristics of mammarian GABA receptors. Int. Rev. Neurobiol. 24, 181-212 (1983)

20 Olsen, R.W.: GABA-benzodiazepine-barbiturate receptor interactions. J. Neurochem. 37, 1-13 (1981) 